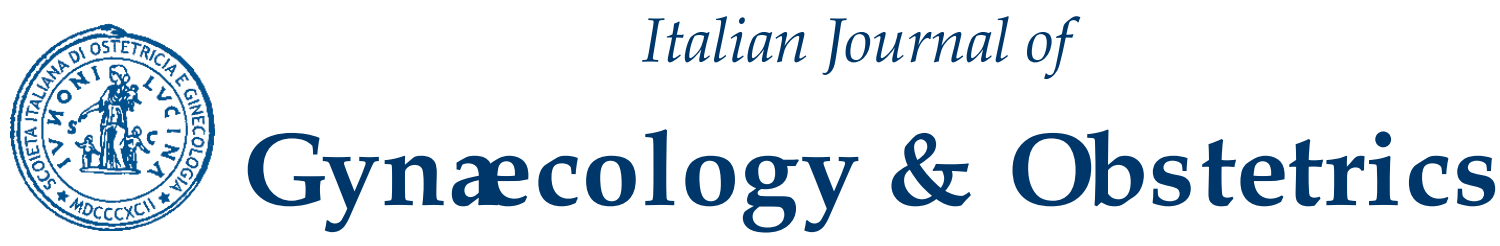

June 2020 - Vol. 32 - N. 2 - Quarterly - ISSN 2385 - 0868

\title{
Polycystic Ovary Syndrome in adolescents: an update
}

\section{Caserta ${ }^{1}$, A. Gregnuoli ${ }^{2}$}

${ }^{1}$ Department of Obstetrics and Gynaecology, Santa Maria degli Angeli Hospital, Azienda Sanitaria Friuli Occidentale, Pordenone, Italy 2Department of Medicine, Endocrinology Unit, Santa Maria degli Angeli Hospital, Azienda Sanitaria Friuli Occidentale, Pordenone, Italy

\section{ABSTRACT}

Menstrual disorders and evidence of hyperandrogenism are characteristic signs of polycystic ovary syndrome (PCOS) in Teens. Diagnosis of PCOS is difficult as clinical signs that distinguish it can be also found in the general population. Specific etiology of PCOS is unknown but it is a complex disease that results in genetic, intrauterine, ectopic and environmental factors. Obesity and insulin resistance are factors commonly associated with PCOS and, as a result, patients are at risk of metabolic and cardiovascular diseases.

Changes lifestyle and drug therapy are recommended in all patients in order to control and counteract development of hyperandrogenism and menstrual disorders.

\section{SOMMARIO}

I disordini mestruali e il riscontro di iperandrogenismo sono segni caratteristici della sindorme da ovaio policistico. (PCOS) negli adolescenti. La diagnosi di PCOS è difficile in quanto i segni clinici possono esser riscontrati anche nella popolazione generale. L'eziologia specifica della PCOS è sconosciuta ma si tratta comunque di una malattia complessa in cui sono coinvolti fattori genetici, intrauterini, ectopici ed ambientali. Obesità ed insulinoresistenza sono fattori comunemente associati alla PCOS e, di conseguenza, i pazienti sono ad alto rischio di malattie metaboliche e cardiovascolari. Modifiche allo stile di vita e terapia farmacologica sono raccomandate in tutte le pazienti al fine di controllare e contrastare lo sviluppo di ipernadrogenismo e disordini mestruali. 


\section{INTRODUCTION}

Polycystic ovary syndrome (PCOS) affects 3.5$15 \%$ women in reproductive age $(1,2)$. It is the most common cause of hyperandrogenism and anovulatory infertility in this age group $(3,4)$. Characteristic clinical signs in women are:

- menstrual irregularities (oligomenorrea or amenorrea),

- clinical hyperadrogenism (hirsutism, acne, androgenic alopecia and anovulatory infertility) (5).

- Rarely, women can present virilisation(6).

Diagnostic criteria used for PCOS have been changes over time as shown in Table $I$.

Table I. Diagnostic criteria used for PCOS over time

\begin{tabular}{|l|l|}
\hline 1990 & $\begin{array}{l}\text { - National Institute of Health: PCOS de- } \\
\text { fined as clinical or biochemical hyper- } \\
\text { androgenism and oligo-anovulation in } \\
\text { the absence of other endocrinopathies } \\
\text { (7). }\end{array}$ \\
\hline 2003 & $\begin{array}{l}\text { - Rotterdam consensus: broadening the } \\
\text { criteria to include the presence of at least } \\
\text { two of the fol-lowing as diagnostics for } \\
\text { PCOS: 1. Biochemical or clinical Hyper- } \\
\text { androgenism, 2. Oligo-anovulation, 3. } \\
\text { Polycystic ovarian morphology to ultra- } \\
\text { sound examination (PCOM)(8). }\end{array}$ \\
\hline 2012 & $\begin{array}{l}\text { - NIH: confirmed Rotterdam 2003 criteria } \\
\text { for PCOS diagnosis but are to be speci- } \\
\text { fied different phenotypes (9). }\end{array}$ \\
\hline
\end{tabular}

PCOS is an heterogeneous disease in terms of both pathophysiology and severity of clinical consequences. Not all patients show all clinical signs or are exposed to the same degree of longterm health risk.

The adoption of the Rotterdam criteria, and in particular the decision to consider two of the three typical elements of the syndrome sufficient for diagnosis, has resulted in different clinical presentations within the same PCOS name, the so-called PCOS phenotypes:

- "classic": when oligoanovulation and hyperandrogenism are present, with or without the micropolycistic aspect of the ovary,

- "ovulatory": when hyperandrogenism and micropolychistic aspect are present,

- "normoandrogenic": in presence of oligoanovulation and micropolycistic aspect.

In this subdivision, the NIH also recommends distinguishing within the classical phenotype subjects with or without ovarian micropolycistic appearance. The former, therefore, have all the manifestations of the syndrome, but it is not clear whether a difference limited to ovarian morphology alone implies real physiopathological and clinical differences.

Women with phenotype A (hyperandrogenism and oligomenorrhoea) present a higher risk than non-hyperandrogenic PCOS.

\section{PATHOGENESIS}

The exact aetiology of this disorder is yet to be clarified but insulin resistance and compensatory hyperinsulinism have been seen, however, to play a central role in the pathogenesis (10). As already mentioned, it is a complex multifactorial disease with an interaction of several factors: genetic predisposition, insulin resistance, dysfunction of beta pancreatic cells, abnormal ovarian and adrenal steroidogenesis and alterations of steroid metabolism, neuroendocrine influences, environmental factors, epigenetic mechanisms and abnormal adaptation to reduction or excess of energy.

\section{Hyperandrogenism}

PCOS is primarily an ovarian disease with increased androgen production. The cells of the theca produce androgens under control of $\mathrm{LH}$ and various intracrine factors. P450c17 is an enzyme that plays a central role in the synthesis of androgens. Its increased expression, as well as the enzyme CYP17A1, is evaluable in the cells of the theca of women with PCOS (11). Hyperinsulinemia, associated with PCOS, exaggerates the response of the cells of the theca to circulating LH. Ovaries with PCOS also have an increased expression of enzymes involved in the 
production of dihydrotestosterone (12).

In patients with PCOS there are also increases in androgens 11-oxygenates, 11 beta hydroxyandrostenedione, 11 ketoandrostenedione, 11 beta hydroxyitestosterone, 11 ketotestosterone. In $20-30 \%$ of women, DHEA and DHEA sulphate are increased.

\section{Insulin-Resistance}

Insulin resistance and hyperinsulinemia play a central role in the pathogenesis of PCOS with a high prevalence found in women and adolescents with PCOS (13).

Regardless of the BMI, this disorder affects thin and obese women.

Insulin resistance in patients with PCOS is determined due to complex interactions involving genetic predisposition, intrauterine factors, early puberty and adiposity.

Insulin resistance is selective tissue and is present in muscle, liver and adipose tissue, mainly due to the metabolic effects of insulin.

Obesity is the most common sign of PCOS. Obesity, especially abdominal obesity, worsens the clinical and hormonal picture of PCOS. It is reported that about $30-40 \%$ of adolescents with PCOS are overweight or obese $(14,15)$. Despite the high prevalence, however, obesity or insulin resistance are not included in the diagnostic criteria of PCOS. However, these confer a high risk of various metabolic abnormalities such as type 2 diabetes, hypertension, dyslipidaemia or metabolic syndrome in these patients.

\section{Genetics}

Familial clustering of hyperandrogenism, anovulation and PCO suggest an underlying genetic basis or cause. Studies in large families have suggested autosomal dominant inheritance, with premature balding as the male phenotype. Other studies of siblings and parents of women with PCOS have observed high prevalence of hyperinsulinemia and hypertriglygeridemia, PCOS in females and premature balding in males.
Nearly $50 \%$ of sisters of women with PCOS have elevated total or bioavailable testosterone concentrations and approximately 35\% of mothers also are affected. The first degree relatives of women with PCOS also exhibit other metabolic abnormalities such as dyslipidemia, which may predispose to an increased risk for cardiovascular disease. These observations further suggest a genetic predisposition or susceptibility.

The genetic component contributes to $70 \%$ of the pathogenesis of PCOS.

Genome wide association studies (GWAS) $(16,17)$ have begun to identify several possible candidate genes, including the DENND1A (differentially espressed in normal and neoplastic cell domain-containing protein 1A) and THADA (thyroid adenoma-associated protein) genes. Further support for DENND1A comes from studies demonstrating increased levels of the V2 isoform of DENND1A in theca cells obtained from women with PCOS18. Currently, PCOS is best seen as a polygenic disorder involving the interaction of numerous genomic variants and the influence of environmental factors. Candidate genes include the long list of molecole (Table II) that partecipate in any of the metabolic and reproductive pathways affected in the syndrome, emphasizing yet again that PCOS is not a specific endocrine disorder, but a result of chronic anovulation due to a wide variety of causes.

\section{DIAGNOSIS OF PCOS}

\section{Hyperandrogenism}

Hyperandrogenism in teens is related to the development of hirsutism, acne, menstrual irregularities and alopecia. Hirsutism is characterized by the growth of terminal hairs in androgen-dependent areas with patterns similar to those of men. The prevalence varies with ethnicity, being greater in Mediterranean, Caucasian white, Hispanic and Middle Eastern women19, lesser in Chinese women (20). Alopecia is less common in teenagers.

Acne comedonale is, instead, common in adolescents (21). Where this symptom is resistant to 
Table II. Genetics of PCOS

\begin{tabular}{|l|l|l|}
\hline Genes & Chromosome & Function \\
\hline LHCGR & Chromosome 9 & Gonadotropin action \\
\hline FSHR & Chromosome 2 & Gonadotropin action \\
\hline THADA & Chromosome 2 & Apoptosis \\
\hline DENND1A & Chromosome 2 & Endocytosis, receptor-mediated turnover \\
\hline YAP1 & Chromosome 11 & Cell proliferation \\
\hline GATA4 & Chromosome 8 & Transcription factor \\
\hline C9orf3 & Chromosome 9 & Aminopeptidase \\
\hline HMGA2 & Chromosome 12 & Transcriptional regulated factor \\
\hline TOX3 & Chromosome 16 & Chromatin remodeling \\
\hline INSR & Chromosome 19 & Insulin signaling \\
\hline SUMO1P1 & Chromosome 20 & Cell proliferaton \\
\hline KCNA4/FSHB & Chromosome 11 & Gonadotropin action \\
\hline ERBB4 & Chromosome 2 & Mitogenesis and differentiation \\
\hline RAD50 & Chromosome 5 & DNA repair \\
\hline KRR1 & Chromosome 12 & Ribosome biogenesis \\
\hline RAB5B, SUOX & Chromosome 12 & Protein transport, breakdown \\
\hline
\end{tabular}

therapy, the suspicion of hyperandrogenism must be placed.

Biochemical hyperandrogenism is documented by free or total testosterone. In addition, about $10-15 \%$ of patients, may have an increase in adrenal androgens, DHEA-S or Androstenedione. The detection of menstrual irregularities in adolescence, in the early years of the menarche, is very common. The average age of the menarche in the population is $12-13$ years. In the first year after the menarche, $60 \%$ of girls have 10 cycles per year and this can last up to 5 years. The finding of amenorrhoea or menstrual cycles $>90$ days after one year from the menarche should suggest hyperandrogenism.

In adolescence, chronic anovulation may also be common in girls with dysfunctional uterine bleeding, although this may also occur in regular cycles.

The finding of a low to medium serum luteal progesterone level confirms anovulation. According to international guidelines, oligo-anovulation must be considered if menstrual intervals shorter than 20 or longer than 45 days persist 2 years after the menarche.

PCOS diagnosis should be considered in girls with final height obtained and puberty development but who have primary amenorrhea.

\section{Polycystic ovarian morphology (PCOM)}

The Rotterdam criteria in 2003 included PCOM as one of the criteria for the diagnosis of PCOS. On TV ultrasound examination, the ovaries of women with PCOS, in addition to having many small follicles, have an increase in size and stromal volume as well as a classic topographic relationship between the follicles and the stroma. The many small follicles are arranged peripherally and surround a dense central stroma of a polycystic ovary.

According to The Rotterdam consensus criterion, PCOM is characterized by the presence of ovaries with a volume $>10 \mathrm{~mL} 3$ and the presence of a total number of small follicles ranging in size from 2 to $9 \mathrm{~mm}$ for a number equal to or greater than 1222 (Figures 1-2); the presence of at least one of these two morphological ultrasound signs in an ovary serves as a meeting the Rotterdam Criteria for polycystic ovary. The prevalence of PCOM in adolescents is 35-40\%23. The prevalence of PCOM is quite high in women with hyperandrogenemia (> 80\%). Despite this, however, both in one on three cases of women 
with regular menstrual cycles without PCOS, and in $14 \%$ of women who use oral contraceptives you can find PCOM.

In addition, PCOM is commonly observed during normal adolescence and in women with hypothalamic amenorrhea and hyperprolactinemia. PCOM should not be confused with a multi-follicular pattern defined by the presence of more than 6 follicles of $4-10 \mathrm{~mm}$ distributed in the ovary.
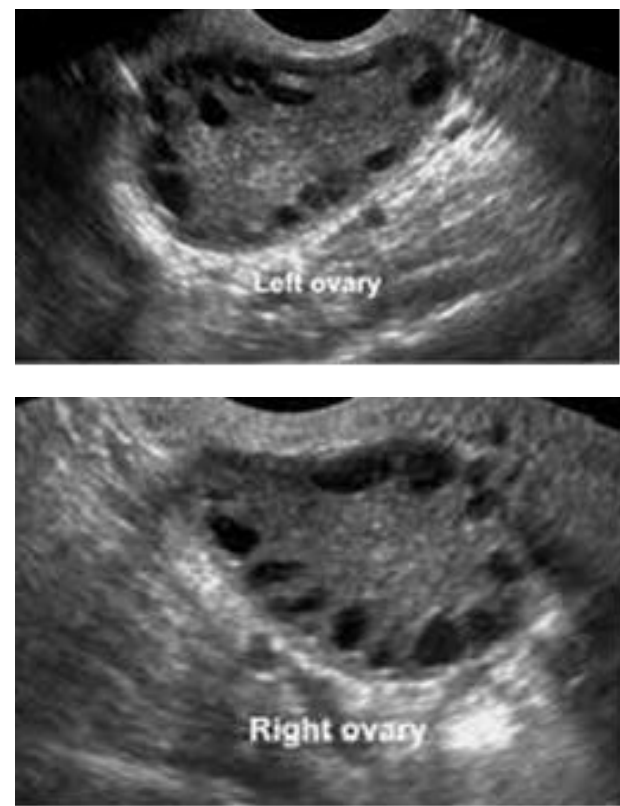

Figure 1. Ultrasound features of the PCOS.

\section{Other features of the PCOS}

PCOS has other common fatures besides hyperandrogenism and ovulatory disfunction that are not included in any diagnostic criteria, including:

- abnormal of gonadotropin secretion,

- insulin resistance and related metabolic abnormalities (p.e. dyslipidemia)

\section{EXCLUSION OF OTHER ANDROGEN EXCESS DISORDERS}

The diagnosis of PCOS is secondary to the exclusion of other pathological patterns responsible for oligo-anovulation and hyperandrogenemia (Table III).

These conditions are:

Thyroid disorders

- Hyperprolactinemia

- Cushing's syndrome

- Non classical congenital adrenal hyperplasia

- Ovarian or adrenal secrete androgenic tumors.

Table IIII. Diffential Diagnosis with other androgen excess disorders.

\begin{tabular}{|l|l|}
\hline Diagnosis & Method of exclusion \\
\hline Thyroid disorders & $\begin{array}{l}\text { serum thyroid-stim- } \\
\text { ulating hormone, } \\
\text { TSH }\end{array}$ \\
\hline Hyperprolactinemia & Serum PRL \\
\hline $\begin{array}{l}\text { Nonclassical Congeni- } \\
\text { tal Adrenal Hyperpla- } \\
\text { sia }\end{array}$ & $\begin{array}{l}\text { a follicular phase } \\
\text { morning serum 17- } \\
\text { OHP concentration } \\
\text { less than 200 ng/dL }\end{array}$ \\
\hline $\begin{array}{l}\text { Androgen Secreting } \\
\text { Ovarian and Adrenal } \\
\text { Tumors }\end{array}$ & $\begin{array}{l}\text { serum total testos- } \\
\text { terone concentration } \\
\text { grater than 150 } \\
\text { ng/dL }\end{array}$ \\
\hline Cushing Syndrome & $\begin{array}{l}\text { overnight dexame- } \\
\text { thasone soppression } \\
\text { test }\end{array}$ \\
\hline
\end{tabular}

1. Thyroid disorders

They are associated in teens with menstrual dysfunction. The overall high prevalence of thyroid dysfunction in teens warrants specific testing to exclude the diagnosis (serum thyroid-stimulating hormone, TSH) in all anovulatory girls, including those with hyperandrogenism, but not for diagnosis of PCOS.

\section{Hyperprolactinemia}

The high prevalence of hyperprolactinemia among girls with menstrual dysfunction justifies specific testing to exclude the diagnosis in all anovulatory girls, but not for diagnosis of PCOS. 
3. Nonclassical Congenital Adrenal Hyperplasia

Congenital adrenal hyperplasia $(\mathrm{CAH})$ is caused by adrenal steroidogenic enzyme defects that result in excessive adrenal androgen production. The most common cause is 21-hydroxylase deficiency. Female with nonclassical or "late-onset" form of CAH present during childhood or early adolescence with precocious puberty, or as young adults with signs of hyperandrogenism, very much like those with PCOS. Whereas it is logical to recommend that nonclassical $\mathrm{CAH}$ be excluded in all women with hyperandrogenism, specific testing can be also reserved in case of early onset of hyrsutism (pre- or peri-menarchal, including girls with premature adrenarche) girls with a family hystory of the disorder, and those in high risk ethnic groups (Hispanic, Mediterranean, Slavic, Ashkenzi Jewish). Estrogen-progestin contraceptives and/or antiandrogens are the best choice for the treatment of chronic anovulation and hirsutism in women with nonclassical CAH.

A follicular phase morning serum 17-OHP concentration less than $200 \mathrm{ng} / \mathrm{dL}$ excludes, and a level greater than $800 \mathrm{ng} / \mathrm{dL}$ estabilishes the diagnosis. Concentrations between the two threshold values suggest the possibility, which can be confirmed by performing an ACTH stimulation test, obtaining blood samples before and 60 minutes after administering synthetic ACTH im or iv.

\section{Androgen Secreting Ovarian and Adrenal Tumors}

These are rare events. The possibility of a tumor is excluded by the clinical history and physical examination. A serum total testosterone concentration grater than $150 \mathrm{ng} / \mathrm{dL}$, identifies almost all women with a potential androgen-producing tumor. However, a tumor should be suspected also in girls with rapidly progressive hirsutism, even with a low level of serum testosterone. Transvaginal ultrasonography will identify almost all solid ovarian mass lesions. Adrenal computed tomography (CT) is extremely sensitive for detecting rare androgen-secreting adrenal tumors.

\section{Cushing Syndrome}

It results from excess adrenal cortisol secretion and can be ACTH dependent (pituitary and ectopic ACTH-secreting tumors) or ACTH-independent (adrenal adenomas, exogenous glucocorticoid treatment). The disorder has features commonly observed in girls with PCOS (menstrual dysfunction, hyperandrogenism, central obesity). The overnight dexamethasone soppression test is the best single screening test to discriminate. The test is performed by administering $1.0 \mathrm{mg}$ of dexamethasone between $11.00 \mathrm{pm}$ and midnight and measuring the serum cortisol at 8 am the next morning; values less than 1.8 $\mu \mathrm{g} / \mathrm{dL}$ are normal.

\section{ASSOCIATED COMORBIDITIES}

The health consequences of PCOS are linked to obesity, insulin resistance and hyperandrogenemia. There is an increased prevalence of glucose intolerance and diabetes (24), metabolic syndrome (25) and cardiovascular disease (26). All adolescents should undergo blood pressure measurement, glucose load tests and lipid profile (27). The follow up is to be repeated annually in overweight/obese adolescents, with familiarity with diabetes and cardiovascular disorders.

\section{THERAPY}

\section{Lifestyle intervention}

The strong association between obesity, hyperandrogenism and mestrual abnormalities emphasizes the importance of addressing lifestyling issues in women with PCOS, focusing on nutrition and exercise. At least $50 \%$ of women with PCOS are obese. It is important to stress that even a small reduction in weight (2-5\%) can result in significant improvements in metabolic and reproduction function. The loss of abdominal fat may be the best predictor of the effects of weight loss. 
Weight reduction is the first-line management strategy for overweight and obese teens. Weight loss increases SHBG, thereby reducing free androgen levels and decreasing androgen stimulation of the hair and skin. Weight loss also improve ovulatory function.

The benefits of exercise for improving cardiovascular health and decrease risk of diabetes have been demonstrated in the general population. Incorporation of moderate activity into daily activities appears as effective for reducing the risk of developing diabetes and cardiovascular disease as that achieved with vigorous physical activity is more likely to be sustained and is essential for mantaining weight loss over time28-30.

\section{Combined oral contraceptive therapy}

Combined oral contraceptives (COCs) should be considered a first-line drug in adolescents with a certain diagnosis of PCOS for the mestrual abdnormalities associated with chronic anovulation27. COCs decrease adrenal and ovarian androgen production and reduce hair growth in nearly two-thirds of hirsute patients. Treatment with OCs offers the following benefits:

1. The progestin component suppress LH, resulting in diminished ovarian androgen production.

2. The estrogen component increases hepatic production of SHBG, resulting in decreased free testosterone concentration

3. Circulating androgen levels are reduced, including these of DHEAS.

4. Estrogens decrease conversation of testosterone to DHT in the skin by inhibition of 5 alpha reductase.

Low-dose estro progestin or natural estrogen are preferred to reduce the negative action on the metabolic profile, the increase in triglycerides and insulin resistance and increased VTE risk.

\section{Medroxyprogesterone Acetate (MPA)}

Oral or intramuscular administration of MPA successfully treats hirsutism. It directly affects thehypothalamic-pituitary axis by decreasing GnRH production and the release of gonadotropins, thereby reducing testosterone and estrogen production by the ovary. Despite a decrease in SHBG, total and free androgen levels are decreased significantly.

The recommended oral dose for GnRH suppression is 20 to $40 \mathrm{mg}$ daily in divided dosage or 150 mg given intramuscularly every 6 weeks to 3 months in the depot form.hair growth is reduced in up to $95 \%$ of patients. Side effects of the tratment include: amenorrea, depression, bone mneral density loss, headaches, fluid retention, hepatic disfunction and weight gain. MAP is not commonly used for hirsutism

\section{Antiandrogens}

Antiandrogens are effective for the treatment of hirsutism but must be used in combination with highly reliable contraceptive method (e.g. ad intrauterine device) because of their potential to adversely affect sexual development in a male fetus if the patient were to conceive unexpectedly.

Spironolactone is the most commonly used as antiandrogenic drug. The most common dose is 50 to $100 \mathrm{mg}$ twice daily. Women treated with $200 \mathrm{mg}$ for day show a greater reduction in hair shaft diameter than women receiving $100 \mathrm{mg}$ pe day. Maximal inhibition of hirsutism is noted between 3 and 6 months but continues for 12 months. The most common side effect of spironolactone is mestrual irregularity (usually metrorragia), which may occur in over $50 \%$ of patients with a dosage of $200 \mathrm{mg}$ per day. Infrequently other side effects such as mastodinia, urticaria, scalp hair loss may occur.

Other option commonly utilized in clinical practice include finasteride. Most of the improvement in hirsutism with finasteride occorre after 6 months of therapy with $7,5 \mathrm{mg}$ per day. OCs in combination with finasteride are more effective in reducing hirsutism than finasteride alone. It is well tollerate, with minimal hepatorenal toxicity.

Flutamide, a pure nosteroidal antiandrogen, in 
hyperinsulinemic, hyperandrogenemic, nonobese PCOS adolescents on a combination of metformin (850 $\mathrm{mg}$ per day) and flutamide $(62,5$ mg per day), and the low-dose OC containng The combination of echini-drospirenone, metfromin and flutamide is effective in reducing excess total fat, abdominal fat, and attenuating dysadipocytokinemia in young women with hyperinsulinemic PCOS. Flutamide is poorly used because it is hepatotoxic even if the dose of 1 $\mathrm{mg} / \mathrm{kg} /$ day is not hepatotoxic (31).

Eflornithine is a reversibile inhibitor of ornithine decarboxylase, an enzyme that is needed for cell division and eflornithine hydrochloride is available as a topical treatment that, $\mathrm{f}$ applied regularly, as effective in slowing the growth of unwanted facial hair.

\section{Metformine}

It is an insulin sensitizer that has shown beneficial effect on weight, metabolic parameters especially glucose tolerance and mestrual irregularity in adolescents $(29,32)$.

Most of the studies are limited by small sample size and short study duration (usually 16-24 weeks).

No serious adverse events have been reported. drospirenone, resulted in a more effective and more efficient reduction in total and abdominal fat excess than was demonstrated by those utilizing an OC with gestodene as the progestin.

The recent guidelines state that the metformin, in addition to lifestyle interventions, can be used in adolescents diagnosed with PCOS or PCOS symptoms before reaching a certain diagnosis.

\section{SUMMARY}

PCOS is an heterogeneous condition with hyperandrogenism and menstrual irregularity as its key signs. The exact aetiology of this condition remains unknown. Diagnosis of PCOS in adolescence is difficult because clinical signs of PCOS cannot be differentiated from physiological conditions of puberty. Obesity, insulin resistance, hyperinsulinemia are common associated and play a role in the pathogenesis. Because these patients have a high risk of developing diabetes, dyslipidemia, hypertension and cardiovascular disease, lifestyle changes are recommended in all patients with PCOS.

Oral contraceptives, antiandrogenic drug and metformin alone or in combination, are used to treat clinical signs of hyperandrogenemia. 


\section{REFERENCES}

(1) Gill H, Tiwari P, Dabadghao P. Prevalence of polycystic ovary syndrome in young women from North India: a Community-based study. Indian J EndocrinolMetab 2012 Dec: 16(Suppl 2): S389-92.

(2) Azziz R, Carmina E, Chen Z, et al. Polycistic ovary syndrome. Nat Rev Dis Primers 2016; 2: 16057.

(3) Azziz R, Sanchez ES, Knochenhauer C, et al. Androgen excess in women: experience with over 1,000 consecutive patients. J ClinicEndocrinol Metab 2004;89:453-62.

(4) Carmina E, Rosato F, Janni A, et al. Extensive clinical experience: relative prevalence of different androgen excess disorders in 950 women referred because of clinical hyperandrogenism. J Clin Endocrinol Metab 2006;91:2-6

5) Fauser BC, Tarlatzis RW, Rebar RS, et al. Consensus on women's health aspects of polycisticovary syndrome (PCOS): the Amsterdam ESHRE/ASRM-Sponsored 3rd PCOS Consensus Workshop Group. Fertil Steril 2012;97:28-38. e25

6)Teede H, Deeks A, Moran I. Polycystic ovary syndrome: a complex condition with psychological, reproductive and metabolic manifestations that impacts on health across the lifespan. BMC Med 2010;8:41

(7) Zawadzki J, Dunaif A. Diagnostic criteria for polycystic ovary syndrome: : towards a rational approach. In: Dunaif A, Gives JR, Haseltine FP, et al., editors. Polycystic ovary syndrome, vol 4. Boston: Blackwell Scientific Publications; 1992. P 377-84.

(8) The Rotterdam ESHRE/ASRM-sponsored PCOS consensus workshop group. Revised 2003 consensus on diagnostic criteria and long-term health risks related to polycystic ovary syndrome (PCOS). Hum Reprod 2004;19:41-7

(9) Johnson T, Kaplan I, Ouyang P, et al. National institutes of health evidence-based methology workshop on polycystic ovary syndrome (PCOS). NIH EbMW report, vol 1. Bethesda: National Institutes of Health; 2012. P. 1-14.
(10) Escobar-Morreale HF, Luque-Ramorez M, San Millan JL. The molecular-genetic basis of functional hyperandrogenism and the polycystic ovary syndrome. Endocr Rev 2005;26:251-82. (11) Nelson VL, Legro RS, Strauss 3 rd JF, et al. Augmented androgen production is a stable steroidogenic phenotype of propagated theca cells from polycystic ovaries. Mol Endocrinol 1999 Jun;13(6):946-57.

(12) Marti N, Galvan JA, Pandey AV, et al. Genes and proteins of the alternatie steroid backdoor pathway for dihydrotestosterone synthesis are espresse in the human ovary and seemenhanced in the polycystic ovary syndrome. Mol Cell Endocrinol 2017 Feb 5;441:116-23.

(13) Diamanti-Kandarakis E, Dunaif A. Insulin resi stance and the polycystic ovary syndrome revisited: an update on mechanisms and implications. Endocr Rev 2012 Dec;33(6):981-1030. (14) Hickey M, Doherty DA, Atkinson H, et al. Clinical, ultrasound and biochemical features of polycystic ovary syndrome in adolescents: implications for diagnosis. Hum Reprod 2011 Jun;26(6):1469-77

(15)Flannery CA, Rackow B, Cong X, et al. Polycystic ovary syndrome in adolescence: impaired glucose tolerance occurs across the spectrum of BMI. Pediatr Diabetes 2013 Feb; 14(1):42-9.

(16) Chen ZJ, Zhao H, He L, et al. Genome-wide association study identifies susceptibility loci for polycystic ovary syndrome on chromosome 2p16. 3, 2p21 and 9q33. 3. Nat Genet 2011;43 (1):55e9.

(17) Shi Y, Zhao H, Cao Y, et al. Genome-wide association study identifies eight new risk loci for polycystic ovary syndrome. Nat Genet 2012;44(9):1020e5.

(18) McAllister JM, Legro RS, Modi BP, et al. Functional genomics of PCOS: from GWAS to molecular mechanisms. Trends EndocrinolMetab 2015;26(3):118e24.

(19) Martin KA, Chang RJ, Ehrmann DA, et al. Evaluation and treatment of hirsutism in premenopausal women: an endocrine society clinical practice guideline. J ClinEndocrinolMetab 2008;93:1105e20. 
(20) Li R, Qiao J, Yang D, et al. Epidemiology of hirsutism among women of reproductive age in the community: a simplified scoring system. Eur J Obstet Gynecol Reprod Biol 2012; 163:165 e9.

(21) Eichenfield LF, Krakowski AC, Piggott C, et al. Evidence-based recommendations for the diagnosis and treatment of pediatric acne. Pediatrics 2013;131:S163e86.

(22) Balen AH, Laven JS, Tan SL, et al. Ultrasound assessment of the polycystic ovary: international consensus definitions. Hum Reprod Update 2003 Nov-Dec;9(6):505e14.

(23) Merino PM, Villarroel C, Jesam C, et al. New diagnostic criteria of polycystic ovarian morphology for adolescents: impact on prevalence and hormonal profile. Horm Res Paediatr 2017;88(6):401e7.

(24) Palmert MR, Gordon CM, Kartashov AI, et al. Screening for abnormal glucosetolerance in adolescents with polycystic ovary syndrome. J Clin Endocrinol;87:1017e1023.

(25) Coviello AD, Legro RS, Dunaif A. Adolescent girls with polycystic ovary syndrome have an increased risk of the metabolic syndrome associated with increasing androgen levels independent of obesity and insulin resistance. J Clin Endocrinol Metab 2006;91:492e7

(26) Hughan KS, Tfayli H, Warren-Ulanch JG, et al. Early biomarkers of subclinical atherosclerosis in obese adolescent girls with polycystic ovary syndrome. J Pediatr 2016 Jan;168:104e11. e1

(27) Teede HJ, Misso ML, Costello MF, et al. International PCOS Network. Recommendations from the international evidencebased guideline for the assessment and management of polycystic ovary syndrome. ClinEndocrinol (Oxf). 2018 Sep;89(3): 251e68.

(28) Lass N, Kleber M, Winkel K, et al. Effect of lifestyle intervention on features of polycystic ovarian syndrome, metabolic syndrome, and intima-media thickness in obese adolescent girls. J ClinEndocrinolMetab 2011 Nov;96(11):3533e40. (29) Hoeger K, Davidson K, Kochman L, et al. The impact of metformin, oral contraceptives, and lifestyle modification on polycystic ovary syndrome in obese adolescent women in two randomized, placebo-controlled clinical trials. J ClinEndocrinolMetab 2008 Nov;93(11):4299e306 (30) Brennan L, Teede H, Skouteris H, et al. Lifestyle and behavioral management of polycystic ovary syndrome. J Womens Health (Larchmt). 2017 Aug;26(8):836e48.

(31) de Zegher F, Ib_a nez L. Therapy: low-dose flutamide for hirsutism: into the limelight, at last. Nat Rev Endocrinol 2010 Aug;6(8):421e2. (32) Ladson G, Dodson WC, Sweet SD, et al. Effects of metformin in adolescents with polycystic ovary syndrome undertaking lifestyle therapy: a pilot randomized double-blind study. Fertil Steril 2011 Jun 30;95(8):2595e8. e1-6. 